\title{
Estética y hermenéutica: ¿Una revitalización de lo incompatible? Sobre la ontología del arte como praxis reflexiva en Georg W. Bertram
}

\author{
Aesthetics and hermeneutics: A revitalization of the incompatible? On \\ the ontology of art as reflexive praxis in Georg W. Bertram
}

Esteban Alejandro Juárez*

\begin{abstract}
Resumen: En las últimas décadas, la tendencia a pensar la estética a partir del carácter autónomo de su objeto ha sido dominante en la discusión filosófica alemana. Sin embargo, la crítica a la estética de la autonomía ha cobrado recientemente un nuevo aliento. Uno de los intentos más ambiciosos por destronar la centralidad de este paradigma en la estética actual corresponde al filósofo Georg W. Bertram. El propósito de este artículo es reconstruir la teoría estética de Bertram y exponer cómo ella se inserta en la disciplina estética. Paralelamente, se mostrarán algunas dificultades de la revitalización de una ontología del arte basada en la continuidad entre praxis artística y vida cotidiana.
\end{abstract}

Palabras clave: praxis artística, estética hermenéutica, autonomía, valor del arte, G. W. Bertram

Abstract: In the last few decades, the tendency to think aesthetics from the point of view of the autonomous character of its object has dominated the discussions in the German philosophical context. However, the criticism of the aesthetics of autonomy has recently taken on a new lease of life. One of the most ambitious attempts to dethrone the centrality of the autonomy paradigm in today's aesthetics is the one carried out by philosopher Georg W. Bertram. The purpose of this article is to reconstruct Bertram's aesthetic theory and to explain how it fits into the current German philosophical debates. Parallelly, it will show some difficulties related to the

\footnotetext{
* Doctor en Filosofía. Profesor de la Facultad de Ciencias de la Comunicación y de la Facultad de Filosofía y Humanidades de Universidad Nacional de Córdoba. Ha realizado estancias de posgrado en la Goethe-Universität (Frankfurt a. M., Alemania). Ha publicado, junto a M. Verónica Galfione, El devenir de la apariencia. Perspectivas estéticas contemporáneas (2018), Arte, belleza y felicidad (2016) y Modernidad estética y filosofia del arte. La estética alemana después de Adorno (2013). Dirección de correo electrónico: esteban.alejandro.juarez@unc.edu.ar
} 
revitalization of an ontology of art based on the continuity between artistic praxis and everyday life.

Keywords: artistic praxis, hermeneutic aesthetics, autonomy, value of art, G. W. Bertram

A fines de la década de 1960, Theodor W. Adorno pudo escribir contra la encumbrada tradición hermenéutica alemana que la tarea de la estética filosófica era comprender las obras de arte en su incomprensibilidad. ${ }^{1} \mathrm{La}$ pretensión de captar la totalidad del sentido no cabría a los objetos del arte porque ellos rehusarían asimilarse a la comprensión y la explicación intelectual. Por supuesto, la sentencia adorniana no rechazaba la comprensión del arte en sí, su relación con el sentido. Concebir una obra de arte fuera de su relación con el sentido no sólo condenaría la vida de una obra a su mera facticidad, sino también pondría en entredicho a las mismas actividades de interpretación que implican, por ejemplo, la redacción de una estética filosofía o una teoría del arte. La comprensión era aceptada, más aún, era estimulada por el objeto mismo, siempre que cristalizara como rebelión contra el sentido. Esta negación determinada del carácter hermenéutico de las obras permitía perfilar un criterio de distinción para los objetos estéticos frente a las actividades comprensivas del campo del saber teórico y del saber práctico, o frente a los procesos de interpretación en la automatizada vida cotidiana.

En contraste, las reflexiones de Hans-Georg Gadamer y del grupo de investigación Poetik und Hermeneutik apuntaban a revigorizar el lazo entre hermenéutica y estética. ${ }^{2}$ Para justificar este vínculo debían sacar a la luz los supuestos problemáticos subyacentes en la noción de autonomía, la cual, desde los tiempos de Karl Moritz e Immanuel Kant, había ocupado el centro del régimen estético de la modernidad. En vez de ceñirse a los rasgos particulares que determinan su distancia de otras esferas del mundo de la vida, los trabajos

\footnotetext{
1 Adorno, Theodor W., Ästhetische Theorie, Frankfurt a. M., Suhrkamp, 1973, p. 179.

${ }^{2}$ Cfr. Gadamer, Hans-Georg, "Estética y hermenéutica”, traducido por J. F. Zúñiga, en Daimon. Revista de Filosofía, núm. 12, 1996, y Jauss, Hans-Robert, „Epilog auf die Forschungsgruppe, ,Poetik und Hermeneutik“", en Graevenitz, Gerhart v. y Marquard, Odo (Eds.), Kontingen₹, München, Wilhelm Fink, 1998, pp. 525-534.
} 
de aquéllos acentuaban la integración de las experiencias artísticas a la estructura de la comprensión hermenéutica. El punto de partida común de la absorción hermenéutica de la estética lo suministraba Gadamer al sostener la tesis del carácter lingüístico de la obra de arte: “... en cuanto algo que dice algo, forma parte del orden de todo aquello que hemos de comprender. Pero, por eso, es objeto de la hermenéutica."3

En los años posteriores a la publicación de Teoría estética, la ligazón entre estética y hermenéutica sería puesta nuevamente en duda. ${ }^{4} \mathrm{~A}$ su vez, la alusión a la sentencia adorniana pasaría a ser moneda corriente, incluso dentro de perspectivas refractarias a los supuestos de su dialéctica. Un giro antihermenéutico comenzaba a calar hondo en los círculos especializados. Esto ha sido señalado por Martin Seel en un artículo fechado en 2002 en el que revisa la suerte de aquel vínculo. ${ }^{5}$ Seel constata que a esa altura la estética hermenéutica era percibida como un modelo obsoleto. A esta despedida, que Seel califica de apresurada, habrían contribuido las agudas reflexiones que sus detractores alemanes vendrían sosteniendo a lo largo de más de dos décadas, desde Rüdiger Bubner y Karl Heinz Bohrer hasta Jochen Hörisch, Hans Gumbrecht, Ruth Sonderegger o Christoph Menke. 6 A pesar de sus diferencias, todos ellos habrían exaltado la autonomía de la experiencia estética y la habrían hecho reposar en aquello que niega, subvierte o suspende la realización de un significado, vale decir: en aquello que se opone a la proyección abarcadora de

${ }^{3}$ Gadamer, Hans-Georg, op. cit., pp. 6s.

${ }^{4}$ Una referencia clave es el trabajo de Rüdiger Bubner, „Über einige Bedingungen gegenwärtiger Ästhetik“, en Ästhetische Erfahrung, Frankfurt a. M., Suhrkamp, 1989, pp. 9-51.

${ }^{5}$ Seel, Martin, „Ästhetik und Hermeneutik. Gegen eine voreilige Verabschiedung“, en Die Macht des Erscheinens: Texte zur Ästhetik, Frankfurt a. M., Suhrkamp, 2007, pp. 27s.

${ }^{6}$ Cfr. Bubner, Rüdiger, op. cit:; Bohrer, Karl Heinz, Plötzllichkeit: zum Augenblick des ästhetischen Scheins, Frankfurt a. M., Suhrkamp, 1981; Hörisch, Jochen, Die Wut des Verstehens: zur Kritik der Hermeneutik, Frankfurt a. M., Suhrkamp, 1998; Gumbrecht, Hans, „Das Nicht-Hermeneutische: Skizze einer Genealogie“ en Hüber, Jörg \& Müller, Alois, Die Wiederkehr des Anderen, Basel, Stroemfeld/Roter Stern, 1996; Sonderegger, Ruth, Für eine Ästhetik des Spiels. Hermeneutik, Dekonstruktion und der Eigensinn der Kunst, Frankfurt a. M., Suhrkamp, 2000; Menke, Christoph, La soberania del arte: la experiencia estética según Adorno y Derrida, traducido por R. Sánchez Ortiz de Urbina, Madrid, Visor, 1997. 
la unidad de sentido como prerrequisito estructural de todo acceso a la experiencia, incluida la del arte. ${ }^{7}$

Si bien la crítica a la furia de la comprensión ha dejado en claro que los objetos de ésta no pueden ser captados en su totalidad como procesos de comprensión de sentido, o no pueden ser captados sólo de ese modo, tampoco las estéticas centradas en la autonomía carecerían de problemas a la hora de enfrentar las nuevas tendencias estéticas. Ellas, por lo menos en principio, parecerían poco adecuadas para comprender no sólo las denominadas por Peter Bürger vanguardias históricas, sino también los nuevos desafíos que presentaban las perfomances e instalaciones surgidas en los años sesenta y setenta. Una de las razones de esto residiría en el hecho de que estos movimientos volverían evanescentes tanto los límites entre las artes individuales y sus géneros, como las fronteras entre el arte y la vida ordinaria. ${ }^{8}$ Como suele sucederle a la reflexión filosófica en general, en el apogeo teórico de las estéticas de la autonomía, su objeto parecía encarnar ya algo del pasado. La reacción de los más radicales exponentes de esta estética fue inmunizarse: para garantizar la supervivencia de su núcleo conceptual, negaron el estatus artístico de las nuevas prácticas. Aunque en la filosofía contemporánea del arte la defensa rabiosa de la autonomía modernista ha sido severamente criticada, entre otras razones, por ignorar o desvalorar un gran espectro de experiencias artísticas, no obstante, la argumentación favorable a pensar la lógica específica de lo estético como algo irreductible a la razón teórica y a la razón práctica, o como algo que interrumpe los hábitos de la vida cotidiana, sigue teniendo buena acogida en las discusiones alemanas de las últimas décadas. ${ }^{9}$

\footnotetext{
${ }^{7}$ Gadamer, Hans-Georg, op. cit., p. 8.

${ }^{8}$ Cfr. Rebentisch, Juliane, Estética de la instalación, traducción de G. Calderón, Buenos Aires, Caja Negra, 2018, pp. 9-24; y Feige, Daniel, „Zwei Formen des Ästhetischen, zwei Formen des Alltagsbezugs“", en Paragrana, Vol. 26, núm. 2, 2017, pp. 15-25.

${ }_{9}$ Cfr. Menke, Christoph, La fuerza del arte, traducido por N. Bornhauser Neuber, Santiago de Chile, Metales Pesados, 2017; Seel, Martin: Estética del aparecer, traducido por S. Pereira Restrepo Buenos Aires, Katz, 2010; Sonderegger, Ruth, op. cit. Rebentisch, Juliane, op. cit. Véase también de esta última, „Zur Aktualität ästhetischer Autnomie. Juliene Rebentisch im Gespräch“, en Huber, Tobías y Steinweg, Marcus (Eds.), Inaesthetik. Theses on contemporary art, Berlin/Zurich, Diaphanes, 2008, pp. 103118. Para un panorama más amplio de la estética alemana de los últimos años, véase, Bertinetto, Alessandro y Bertram Georg (Eds.), "Introduzione”, en Il bello dell'esperienza.
} 
Poner en cuestión justamente la posición que ocupa la autonomía en la estética filosófica actual es uno de los objetivos principales del trabajo de Georg W. Bertram, una de las voces más destacadas del reciente debate alemán. En lo que sigue, deseo exponer la teoría estética de Bertram y mostrar el modo en que se inserta en este contexto. A la par, también quisiera presentar algunas dudas sobre el proyecto de una ontología del arte basado en la defensa de la continuidad entre arte y vida cotidiana.

II.

Georg W. Bertram, actual catedrático de la Universidad Libre de Berlín, ha irrumpido en la escena estética alemana con una propuesta teórica que intenta desmarcarse de las filosofías del arte que siguen girando en torno al canon consagrado de la autonomía. La propuesta lleva el nombre de "ontología del arte como praxis reflexiva" $10 \mathrm{y}$ es, sin duda, ambiciosa ${ }^{11}$ y polémica. Ambiciosa, porque proyecta un marco conceptual tan amplio como para abarcar las experiencias estéticas en general, lo cual incluye tanto los fenómenos de estetización de la vida cotidiana como la pluralidad del arte y de las artes. Esto es, no sólo desea explicar las obras modernas y las vanguardias históricas concretas, sino también aquellas manifestaciones artísticas y estéticas contemporáneas que ponen en juego procesos radicales de desdiferenciación. $\mathrm{Y}$, dijimos, polémica, no sólo porque su nervio vital reside en la confrontación con el foco autonomista de la filosofía del arte, sino también porque sustenta

La nuova estetica tedesca, Milano, Christian Marinotti Edizioni, 2016, pp. 5-13.

${ }^{10} \mathrm{El}$ desarrollo más acabado de esta propuesta se encuentra en Bertram, Georg W. Kunst als menschliche Praxis. Eine Ästhetik, Berlin, Suhrkamp, 2014. (El arte como praxis bumana. Una estética, traducido por J. F. Zúñiga, Granada, Comares, 2016). Cfr. también del mismo autor, „Was ist Kunst? Skizze zu einer Ontologie der Kunst“, en Zeitscbrift für Ästhetik. und Allgemeine Kunstwissenschften, Vol. 62, T. 1, año 2017, pp. 77-94. (“¿Qué es el arte? Esbozo de una ontología del arte", traducido por M. J. Varela Salinas, en Estudios Filosóficos, Vol. LXVII, 2018, pp. 263-281.).

${ }^{11}$ Esta ambición ya estaba presente en Kunst. Eine philosophische Einfübrung. Aunque este libro fue concebido como una introducción general a las principales teorías estéticas, contenía muchos de los supuestos que cristalizarían luego en El arte como praxis bumana. Cfr. Bertram, Georg W., Kunst. Eine philosophische Einfübrung, Stuttgart, Philipp Reclam, 2005. 
su crítica, aun a riesgo de ser considerado un proyecto regresivo, religando la estética con el ya no tan reputado modelo hermenéutico, si bien ahora revisado a la luz del pensamiento postanalítico y del postestructuralismo. ${ }^{12}$

Con esta apuesta pareciera que Bertram quisiera exorcizar los fantasmas del antihermeneutismo en estética y compatibilizar lo que para muchos resultaría ya incompatible. Quienes, como Adorno o Menke, separan el arte de las faenas cotidianas, partiendo de la resistencia o el aplazamiento de la comprensión -es decir, a partir de su legalidad específica: ser un objeto no hermenéutico-, no podrían dar cuenta de lo que el arte es y de lo que vale para la vida, porque sólo localizando su valor para la vida se podría saber qué lo distingue de otros asuntos de la vida diaria. La filosofía del arte, por lo tanto, debe partir de la pregunta por el valor del arte para el ser humano. Y quien se acercó más a esta pregunta fue la hermenéutica, no la estética de la negatividad.

De acuerdo con Bertram -de esto trata su idea central- para poder acceder a una compresión estética correcta habría que pensar el arte como una praxis humana relacionada de modo constitutivo con otras prácticas, no como opuestos. Dicho con mayores precisiones: habría que concebir el arte como un acontecimiento dinámico en el que la producción de obras es inseparable de las actividades comprensivas de los receptores y del contexto más vasto de otras prácticas histórico-culturales. Así, inspirado en Martin Heidegger y en Hans-Georg Gadamer, y también en ciertos argumentos de John McDowell, este antiguo discípulo de Albrecht Wellmer, Odo Marquard y Martin Seel pretende renovar en clave hermenéutica las preguntas que impulsan la filosofía del arte. Para él, la exploración estética debe empezar con la tesis de la continuidad del arte con las prácticas de la vida cotidiana. Y, sobre todo frente a Adorno y sus discípulos, debe iniciar su tarea delimitando con precisión las actividades de los receptores cuando se relacionan con obras de arte..$^{13}$ Sólo ateniéndose a estos requisitos la estética podría responder a la pregunta por la

12 Cfr. Bertram, Georg W., Hermeneutik und Dekonstruktion. Konturen einer Auseinandersetzung der Gegenwartsphilosophie, München, Fink, 2002. Cfr. también, Bertram, Georg W., Sprachphilosophie zur Einführung, Hamburg, Junius, 2011.

13 Sobre la crítica a Adorno en este punto, cfr. Bertram, Georg W., "El potencial utópico del arte después de Theodor W. Adorno. Una reactualización", traducido por V. Galfione y E. Juárez, en Galfione, María Verónica y Juárez, Esteban A. (Eds.), Modernidad estética y filosofía del arte. La estética alemana después de Adorno, Tomo I, Córdoba, Ed. 29 de mayo, 2013, pp. 94-101. 
relevancia del arte para la vida.

Pero para justificar una renovada fusión entre estética y hermenéutica no es suficiente posicionarse exclusivamente contra aquellos que entienden la autonomía del arte a partir de su carácter hermético, como artefacto cerrado a la comunicación - de hecho, Bertram no niega ex toto que las obras de arte sean en sí objetos enigmáticos-. ${ }^{14}$ Con la crítica al paradigma de la autonomía Bertram aspira a discutir todas "las posiciones que tratan de pensar el arte recurriendo a su especificidad y a su delimitación frente a otras actividades". ${ }^{15}$ La estrategia que utiliza para ello es encontrar ejemplos de teorías estéticas actuales que sean en muchos aspectos distantes entre sí pero que, sin embargo, se focalicen en la elucidación de caracteres distintivos del arte, más allá de que éste sea entendido como un objeto, una práctica, una experiencia o una institución. Estas diferencias no ofrecerían más que gradaciones de un paradigma sólidamente establecido. A esos ejemplos paradigmáticos los halla en la teoría de la negatividad estética de Menke y en la estética analíticointerpretativa de Arthur Danto. Mientras que una remarca la supresión del sentido que opera en el arte, la otra se orienta por el proceso específico de interpretación que lo diferencia de modalidades no artísticas. A pesar de esta aparente distancia, e incluso a pesar de que la posición de Menke se haya ido modificando y enriqueciendo con el correr de los años, ${ }^{16}$ Bertram intenta demostrar que ambos convergen al determinar de modo abstracto la peculiaridad del arte. ${ }^{17} \mathrm{Y}$ ambos, además, permanecen dependientes del concepto objetivista del arte que Heidegger ya había desactivado en "El origen de la obra de arte". ${ }^{18}$ La consecuencia es que ninguno puede ligar la especificidad del arte con su valor, ni puede explicar concretamente la pluralidad del arte y de las artes. Esto podría lograrse, según Bertram, tomando como objeto de la estética a la variedad de las prácticas de los receptores en su

${ }^{14}$ Cfr. Bertram, Georg W., Kunst. Eine philosophische Einführung, pp. 291-294.

15 Bertram, Georg W. El arte como praxis humana, p. 12.

${ }^{16}$ Sobre esta evolución, cfr. Menke, Christoph, La soberanía del arte; y, del mismo autor, Kraft. Ein Grundbegriff ästhetischer Anthropologie. Mit einem neuen Vorwort, Berlin, Suhrkamp, 2018.

${ }^{17}$ Una crítica a esta equiparación se halla en Zúñiga, José F., "Hermenéutica, autonomía y valor del arte", en Rilce, Vol. 35.1, 2019, pp. 71ss.

${ }^{18}$ Heidegger, Martin, "El origen de la obra de arte", en Caminos de bosque, traducido por H. Cortés y A. Leyte, Madrid, Alianza, 1998, pp. 11-62. 
trato con las obras, sin desatender, a su vez, a los medios y procedimientos artísticos. Para ilustrar esto recurrirá a la idea de autorreferencialidad del arte, uno de los pilares en los que se asienta su trabajo.

En función de la crítica al paradigma de la autonomía, Bertram cree poder roturar el terreno para desplegar los conceptos centrales de su propuesta. Pero antes de avanzar en estos conceptos habría que dejar en claro que con la tesis de la continuidad entre arte y praxis, que ya estaba contenida en los argumentos que tanto Heidegger como Gadamer utilizaron contra el objetualismo y el subjetivismo estéticos modernos, ${ }^{19}$ Bertram no pretende contrarrestar el prematuro adiós dado a la hermenéutica con una nueva (y precipitada) despedida de la autonomía. Es consciente de que abandonar del todo el concepto de autonomía presupondría desconocer el trato histórico con constelaciones artísticas, con materiales específicos, con sus tradiciones y con los conocimientos expertos necesarios para hacer arte y comprenderlo. ${ }^{20}$ También parece advertir que ese abandono supondría vaciar al concepto de arte de su potencial crítico y libertario. Y si su definición de arte se formula como una contribución práctica es, en definitiva, en función de su compromiso con la praxis de la libertad. ${ }^{21}$ Por ello es que su intención polémica remite más bien a una cuestión de desplazamiento de énfasis, esto es: a pensar la autonomía como un aspecto del arte, y no ya más como su núcleo. Así, trata no tanto de negar lo específicamente estético, sino de reorientarlo dentro de una teoría que entiende al arte interconectado estrechamente con otras actividades. Comprendido en el plexo de relaciones prácticas, el arte se determina como una forma peculiar de "praxis reflexiva". La tarea de una estética hermenéutica revitalizada sería entonces elucidar lo específico de la forma de praxis artística, pero partiendo de su relación integral con el resto de las prácticas, para luego aclarar la contribución que, gracias a su especificidad, ofrece a la forma de vida humana. Y lo que tiene que evidenciar como contribución es en qué medida

${ }^{19}$ Cfr. Bertram, Georg W., "¿Qué es el arte? Esbozo de una ontología del arte”, pp. 267s. Para una crítica del subjetivismo de la consciencia estética, cfr. Gadamer, HansGeorg, Verdad y método: fundamentos de una hermenéutica filosófica, traducido por A. Agud y R. de Agapito, Salamanca, Sígueme, 1984, pp. 75-120. Para una crítica de la concepción moderna de autonomía basada en la definición de arte como objeto, cfr. Heidegger, Martin, op. cit., pp. 13s.

${ }^{20}$ Bertram, Georg W., El arte como praxis humana, p. 2.

${ }^{21}$ Ibid., p. 181. 
esta praxis reflexiva participa en la constitución de la libertad.

III.

La noción de "praxis humana" que sustenta esta concepción del arte está respaldada también en Heidegger y Gadamer. "Una praxis humana", así lo asume Bertram, "es una praxis que está ligada a tradiciones". ${ }^{22}$ La praxis está ligada a tradiciones en un sentido estructural. Este carácter estructural quiere expresar lo contrario a cualquier coacción última de un pasado ya acaecido sobre los actos humanos del presente y del futuro. Una tradición permanece vigente porque justamente no puede ser saturada; ella está siempre siendo revisada y renegociada por seres que se autodeterminan en cuanto seres humanos. El horizonte de la praxis es un horizonte abierto, podríamos decir: indeterminado; pero también la praxis es, a la vez, algo determinado, en tanto está inserta en un contexto histórico y cultural que la condiciona. Es decir, para Bertram, la praxis artística está inmersa en una unidad dialéctica de determinación e indeterminación.

Con un razonamiento análogo, Bertram considera que la praxis humana es racional. La racionalidad de la praxis, más que a una determinación última, refiere al proceso de redefinición y crítica constante de los marcos de orientación esenciales dentro de esa forma de vida. ${ }^{23}$ Aquí se le podría exigir a Bertram mayores precisiones, puesto que la racionalidad se perfila en términos tan generales que difícilmente se pueda apelar a ella para diferenciar en la historia concreta aquellos marcos que son esenciales de aquellos que no lo son y, por ende, tampoco se pueda explicar cómo la transformación histórica podría afectar a la misma racionalidad que distingue lo esencial de lo inesencial. ${ }^{24}$ Asimismo es discutible que los procesos de indeterminación se originen de la misma racionalidad de la praxis humana. Bertram se basa aquí en Hegel y en una idea singular de autocomprensión, pero estas referencias no

22 Ibid., p. 38.

${ }^{23}$ Ibid., p. 40.

24 Cfr. Hogh, Philip, „Kraft, Praxis und der blinde Fleck der Geschichte. Zum Geschichtsverständnis in der Gegenwartsästhetik“, en Zeitschrift für kritische Sozialtheorie und Philosophie, Vol. 3, núm. 2, 2016, p. 268. 
parecen alcanzar para explicar concretamente estas cuestiones. ${ }^{25}$

Fundándose en la historicidad estructural de la praxis racional humana, Bertram puede aseverar, en términos abstractos, que ni la tradición se opone a lo abierto, ni la determinabilidad a lo indeterminado. Es cierto que esto le sirve para apartarse de la unilaterialidad que encuentra en Menke y Danto. Mientras que éstos, a pesar de sus divergencias, pensarían en el fondo la praxis humana únicamente como praxis de determinabilidad (Praxis der Bestimmtheit), ${ }^{26}$ Bertram vería en el vínculo entre determinabilidad e indeterminabilidad dos momentos mutuamente articulados en una unidad dialéctica. Y esta unidad es la que le posibilitaría atribuir al arte un lugar significativo en la negociación inagotable por las determinaciones de la praxis humana y, en definitiva, en la conformación de órdenes normativos flexibles.

Se podría objetar, en lo que atañe a la crítica lanzada contra Menke, que Bertram no calibra acertadamente la diferencia de posiciones entre ellos, porque ésta no radica tanto en que uno piensa con amplitud dialéctica lo que el otro piensa de modo unilateral. La diferencia parecería estar marcada más bien por el modo en que ambos comprenden la unidad entre determinabilidad e indeterminabilidad, en términos de Bertram, o entre capacidades y fuerzas, en términos de Menke. En éste tampoco la indeterminabilidad se da sin la determinabilidad. Ambas se dan juntas, aunque se repudien en el modo de su realización. El punto crucial de desencuentro se halla, más bien, en la forma de entender el conflicto entre estos momentos: en Bertram, su confrontación no rompe la continuidad y la complementariedad de su desarrollo; de este modo ambos momentos se despliegan en un proceso racional dinámico, cuya unidad está garantizada por el llamado de la tradición. En Menke, la unidad dinámica de esos momentos sólo se puede leer como cifra de una aporía, como un antagonismo que no es posible trascender y ante el cual lo único que nos queda es tensionarlo hasta sus límites. ${ }^{27}$ Lo que está en disputa, por lo tanto, son dos modelos de la estética alemana, el de una ontología estética o el de una antropología estética, para pensar la relación de lo estético, el poder del sujeto y la crítica a los órdenes normativos. En definitiva, lo que significa el arte para la vida.

\footnotetext{
${ }^{25}$ Bertram, Georg W., El arte como praxis bumana, p. 54.

${ }^{26}$ Ibid., p. 40.

${ }^{27}$ Cfr. Menke, Christoph, Kraft, p. 9.
} 
IV.

Esta disputa, cuyo trasfondo también es un conflicto sobre diferentes formas de entender la subjetividad moderna, ${ }^{28}$ se refleja solapadamente en el lugar que Bertram establece los orígenes filosóficos de la estética. Si Menke había establecido el principio preestético de la estética en Descartes y Leibniz y había reconocido a Baumgarten como su fundador, ${ }^{29}$ Bertram construye una genealogía de esta disciplina comenzando por Kant y Hegel. Se debe partir de ellos porque fueron los que posibilitaron concebir la experiencia estética como praxis reflexiva de sujetos con capacidad de autodeterminación, afirma Bertram. Sin embargo, ni Kant ni Hegel extrajeron de allí, por su fijación en el aspecto cognoscitivo, las consecuencias prácticas del carácter reflexivo del arte. Para hacerlo es necesario dar un salto de la disciplina estética a la teoría de la reflexión, e investigar los procesos de toma de conciencia y autoconciencia.

Desde esta perspectiva, el concepto heredado de praxis adquiere nuevos contornos. Para ir más allá de Kant y Hegel, la praxis reflexiva debe ser entendida ahora no como un acontecimiento cognoscitivo, en el cual el "objeto de la reflexión se objetiva de manera teórica", provocando un distanciamiento conceptual, sino como uno práctico, en "el que uno interviene". ${ }^{30}$ La reflexión se entiende, así, como algo que repercute en otras prácticas. Esto supone la capacidad de un sujeto (individual o colectivo) de producir efectos sobre sí mismo (y sobre otros). Lo cual significa, para Bertram, siguiendo otra vez a Heidegger y a Gadamer, que la reflexión práctica implica la transformación de las prácticas. En relación con el arte, aquí se asevera su carácter productivo, su orientación finalista, contra lo que podría razonar Menke cuando manifiesta que los artistas tienen un poder paradójico, un "poder, no poder". ${ }^{31}$ A su vez, se afirma también que, en cuanto praxis reflexiva, en el arte se lleva a cabo "una

\footnotetext{
${ }^{28}$ Cfr. Menke, Christoph, "Subjetividad estética. Sobre un concepto fundamental de la estética moderna”, en Estética y negatividad, traducción de P. Storandt Diller, Buenos Aires, Fondo de Cultura Económica/ Universidad Autónoma Metropolitana, 2011, pp. 87-118.

${ }^{29}$ Cfr. Menke, Christoph, Kraft.

${ }^{30}$ Bertram, Georg W., El arte como praxis humana, p. 61.

${ }^{31}$ Menke, Christoph, La fuerza del arte, p. 14.
} 
relación temporal e imaginativa llena de expectativas" 32 en el marco de una historicidad estructuralmente inconclusa, en la cual la libertad se redefine una y otra vez. El arte posee un potencial transformador, dice Bertram interpretando a Gadamer, pero dicho potencial ni es una "fuerza" completamente indeterminada del ser humano, como piensa Menke, ni es sólo un potencial de transgresión, como ha pensado, por ejemplo, Jacques Rancière. ${ }^{33}$ Ese potencial puede realizarse también como corroboración de los sujetos en su trato con el mundo. A pesar de que hasta aquí no se podría distinguir la experiencia estética de otras prácticas transformadoras como, verbigracia, la acción política o el acto moral, esto brinda a Bertram las herramientas preliminares para allanar el camino hacia la especificidad del arte, es decir, hacia el modo en que los seres humanos confrontan consigo mismo en el arte, y la medida de su valor. Pero también le permite poner en duda la imagen que Menke tiene de la libertad estética, según la cual el arte no estaría sujeto a fines prácticos, sino que desenvolvería un "juego de fuerzas" como liberación de "lo social en lo social" 34.

\section{V.}

Uno de los conceptos esenciales de la propuesta de Bertram es el de autorreferencialidad (Selbstbezüglichkeit), del cual se vale para acoger a una idea transformada de autonomía estética, ahora redefinida como un aspecto de la conexión arte y praxis. Esta idea, elaborada a partir de un análisis crítico de la materialidad sensible y la autorrefencialidad del arte en Hegel y en Nelson Goodman, supone, en consonancia con las enseñanzas de Wellmer, abandonar la concepción objetivista de la obra artística para pasar a una versión interactivista de la experiencia estética. En esta versión, el arte debe ser comprendido como un "acontecer negociador" 35 (Verhandlungsgeschehen), el cual se basa en lo que Wellmer ha denominado "juego de reflexión estético”. ${ }^{36}$ Por ello entiende que el acontecer artístico se constituye como tal en la interacción

\footnotetext{
32 Bertram, Georg W., El arte como praxis humana, p. 67.

${ }^{33}$ Cfr. Bertram, Georg W., “¿Qué es el arte? Esbozo de una ontología del arte”, p. 270.

${ }^{34}$ Menke, Christoph, op. cit.

${ }^{35}$ Ibid., p. 88.

${ }^{36}$ Wellmer, Albrecht, Versuch über Musike und Sprache, München, Hanser, 2009, p. 146.
} 
entre la producción, la obra y la recepción, si bien Bertram en sus trabajos principales dedica mayor atención a la recepción que a la producción. Sin duda esta atención no desentona con su tesis principal: no se podría pensar el potencial transformador de la configuración propia de una obra soslayando tanto las prácticas por medio de las cuales los receptores interactúan con ella, como las prácticas cotidianas que son perturbadas o confirmadas al ser interpeladas por ella. Sin embargo, se le podría recriminar perder de vista el saber del oficio mismo del artista.

Bertram cree tocar este punto al postular la idea de la constitución autorreferencial de las obras de arte. Pero, con ello, tiene que reintroducir la idea de autonomía. Aquí se apoya en la idea de "ley formal"37 de Adorno, aunque con la crítica al negativismo y al formalismo que, para Bertram, esa idea arrastra en el frankfurtiano, se amortigüe gran parte de su potencia crítica.

Cada obra artística "determina a partir de sí misma la configuración de sus elementos y lo que tiene relevancia en su interior, su dispositivo autorreferencial", ${ }^{38}$ afirma Bertram. Este dispositivo cristaliza en dos espacios de interacciones que se retroalimentan entre sí. El primero es interno, y refiere a la conexión dinámica de elementos y relaciones que una obra de arte conforma desde sí misma, aunque esto comprometa también a otras obras, en tanto que las obras individuales entretejen su propia historia al cobijar, transformadas, constelaciones ejecutadas en otras producciones. El segundo se proyecta hacia afuera, y concierne a las actividades interpretativas de los receptores, que Bertram clasifica en cuatro tipos: emotivas, perceptivas, corporales y simbólicas. Por la circulación entre estos espacios, que es pensada mixturando el concepto de mimesis de Adorno con la concepción de Gadamer sobre la historia efectual, las obras representarían un desafio que podría "condensarse siempre, por parte de los receptores, en actividades nuevas a las que se añaden otras nuevas". ${ }^{39}$ Siguiendo este argumento, puede decir que las actividades específicas del arte, frente a otras actividades no estéticas, son precisamente aquellas que lo revisten de importancia al renegociar una y otra vez las determinaciones de la praxis humana. Esto supone que cada práctica es ya una corroboración de un proceso histórico ininterrumpido de negociaciones

\footnotetext{
37 Adorno, Theodor W., op. cit., p. 17.

${ }^{38}$ Bertram, Georg W., El arte como praxis humana, p. 95.

${ }^{39}$ Ibid., p. 110.
} 
dentro de la totalidad de las prácticas humanas, que son desafiadas a su vez por objetos que se han constituido en un espacio autorreferencial y que tienen la capacidad imaginativa de anticipar y promover transformaciones en otras prácticas.

Es de lamentar que los ejemplos con los que Bertram en su libro principal, Arte como praxis humana, pretende ilustrar las articulaciones entre productores, obras, actividades de recepción y otras prácticas no sean muy elocuentes para justificar las pretensiones críticas del arte. ${ }^{40}$ Pareciera ser dudoso que lo dicho sea suficiente para inferir que los procesos de transformación estética favorezcan la libertad, en el antiguo sentido de autodeterminación humana, en otros ámbitos. Si bien las transformaciones ilustradas pueden fácilmente mostrar procesos de desentumecimiento de la percepción visual (por el trato con una pintura) o de las capacidades lingüísticas (por ver y comentar una película), según los dos ejemplos que da Bertram, también es cierto que las transformaciones estéticas pueden legitimar procesos de disciplinamiento social más eficaces. ${ }^{41}$ Asimismo, puede echársele en falta que, a pesar del rol fundamental de la historicidad en la concepción de la praxis y de la obstinación por comprender la pluralidad de las artes, la historia concreta (y sobre todo la historia concreta de las artes) tenga escasa cabida. ${ }^{42}$

\section{VI.}

$\mathrm{Al}$ final de Arte como praxis humana Bertram intenta responder a algunos de estos posibles reproches, retomando una y otra vez la cuestión del valor del arte. ${ }^{43}$

\footnotetext{
40 Ibid., pp. 115s.

${ }^{41}$ Cfr. Foucault, Michel, Estética, ética y hermenéutica, traducción de A. Gabilondo, Barcelona, Paidós, 1999, pp. 273s.

42 Sobre estas objeciones, cfr. Hogh, Philip, op.cit; cfr. también, Vilar, Gerard, "El concepto de autonomía en la estética alemana reciente", en Estudios Filosóficos, Vol. LVII, 2018, pp. 260s.

43 En su reseña a Arte como praxis humana, Alex Holznienkemper pareciera primero reprocharle a Bertram ser reiterativo con sus tesis, para, acto seguido, concederle un valor pedagógico. Esto es claramente plausible. Pero creo que sería más interesante pensar esas reiteraciones como recapitulaciones en las cuales los temas tratados retornan con pequeñas variaciones, y que esas modificaciones son las que deberían estimular la lectura crítica de sus principales tesis. Cfr. Holznienkemper, Alex, "Kunst
} 
El punto de partida lo suministra una nueva modulación de su tesis principal: si antes se había subrayado la unidad dialéctica entre indeterminación y determinación en el arte, ahora se sostiene que éste es una praxis agonal e insegura. Con la aclaración de estas atribuciones, según Bertram, se podría iluminar su aporte a la libertad.

Bertram intenta esclarecer aquí el significado de lo que denota que el arte sea algo que valga la pena en tanto praxis crítica de autodeterminación. Lo hace en cinco pasos. El primero retoma el tema de la pluralidad de las artes. En discusión con la construcción hegeliana del sistema de las artes, Bertram plantea que las obras individuales y las artes particulares se desenvuelven en un contexto abierto, en donde son constantemente reactualizados los patrones, o "constelaciones genéricas", que sirven de soporte dinámico a la autoconstitución de las obras y de las artes. Esto también es significativo para las actividades interpretativas de los receptores porque ellos ejercitan y pulen sus capacidades en el trato con las constelaciones. Y en tanto las actividades relacionadas con el arte refieren a prácticas extraestéticas, la praxis artística repercute en el quehacer cotidiano. El arte inicia así un juego de reflexión integral en el contexto de la praxis del mundo de la vida. ${ }^{44}$

El segundo paso apunta al concepto de experiencia estética, concepto que supo signar las discusiones estéticas de las últimas décadas en Alemania. Con él, los filósofos pasaron a interrogarse no ya por la constitución de los objetos estéticos, sino por las prácticas que se ponen en juego en el trato con ellos. En este marco, Bertram caracteriza la experiencia estética, prosiguiendo algunas reflexiones de Seel, ${ }^{45}$ como la experiencia de "la falta de autonomía en la autonomía". ${ }^{46} \mathrm{Al}$ experimentar estéticamente, los receptores se comportan de un modo activo frente a la configuración autorreferencial del objeto, realizando prácticas crítico-interpretativas determinadas, y, al mismo tiempo, son pasivos, al dejarse orientar por esa configuración específica. Sin este dejarse

als menschliche Praxis. Eine Ästhetik by Georg W. Bertram (review)", en Monatshefte, Vol. 109, núm. 4, 2017, p. 681.

${ }^{44}$ Bertram, Georg W., El arte como praxis humana, p. 140.

45 Cfr. Seel, Martin, "Dejarse determinar. Un concepto revisado de autodeterminación", en El balance de la autonomía. Cinco ensayos, traducido por J. Ancona, Barcelona, Anthropos, 2010, pp. 59-84.

${ }^{46}$ Bertram, Georg W., El arte como praxis bumana, p. 141. 
orientar no habría ningún desafío a sus actividades. Y este ser desafiado del arte conlleva, como ya se ha sugerido, un estar abierto, un momento de indeterminación, algo que escapa a nuestro control por medio de capacidades cognoscitivas o prácticas. Pero, por supuesto, Bertram no encuentra allí ningún hiato irreductible, como sí percibiría Menke. A partir de estos razonamientos, Bertram llega a la conclusión de que la falta de autonomía en la autonomía sería lo que hace que una experiencia sea específicamente estética: por su mediación, los seres humanos se autodeterminan a través de actividades en las que no son autónomos, en tanto que interviene el cuasi heterónomo dejarse guiar por las constelaciones de la obra. Aquí queda la duda si esto realmente explica la especificidad del arte puesto que, como el mismo Seel muestra, la oscilación entre determinar y dejarse determinar también es propia de, por ejemplo, las acciones morales.

En el tercer paso el autor se propone avanzar en la delimitación del sentido en que la praxis de la falta de autonomía en la autonomía tiene como afán ser valiosa, es decir, en qué medida contribuye a la libertad, ya que sin este paso no se podría aseverar que la falta de autonomía en la autonomía sea lo específico de la experiencia estética. Lo que es clave aquí es el carácter agonal que se le atribuye al arte, lo cual se traduce, en términos de Bertram, en que las obras de arte contienden entre sí por entregar constelaciones desafiantes. ${ }^{47} \mathrm{De}$ ahí su carácter logrado o malogrado. Esto sería fundamental, ya que la disputa se orientaría por la pretensión de aportar algo a la determinación de la praxis humana, a su autodeterminación. Y como el logro, en razón de su carácter histórico y agónico, nunca puede estar garantizado de una vez por todas, entonces las prácticas artísticas son constitutivamente inseguras, lo que para Bertram es sinónimo de su modernidad. El arte es, visto desde esta perspectiva, esencialmente moderno.

El cuarto y el último paso complementan al anterior en el plano de la recepción. Sin los juicios normativo-evaluativos de los espectadores, que no son juicios subjetivos, sino que tienen su suelo en el mundo objetivo de los receptores, ${ }^{48}$ la pretensión litigante de las obras de ser la ejecución

\footnotetext{
${ }^{47}$ Ibid., p. 153.

${ }^{48}$ Este juicio se apoya, no sin algunas reservas, en los análisis de John McDowell. Cfr. McDowell, John, Mente y mundo, traducción M. A. Quintana Paz, Salamanca, Ediciones Sígueme, 2003.
} 
paradigmática del arte quedaría trunca. Con los juicios críticos sobre la pretensión del logro estético, tanto los productores como los receptores toman posición respecto a las determinaciones que las obras configuran. Y, mediante ellas, también se posicionan respecto a las determinaciones de otras prácticas. Los impulsos para fomentar su autodeterminación surgen precisamente de la discusión con el acontecer negociador del arte.

Ante este proyecto se podría apelar una vez más a aquella advertencia adorniana que Rainer Rochlitz lanzara contra el maestro de Bertram: "El riesgo de tal estética", Rochlitz se refiere a la estética comunicativa de Wellmer, "es reducir el fulgor inaudito del arte a un mensaje expresable por medios discusivos y diluir el hiato entre dos formas de lenguaje irreductibles: de amortiguar el choque." 49

VII.

Tanto en Arte como praxis humana como en su artículo "¿Qué es el arte? Esbozo de una ontología del arte", Bertram parece ser consciente de los problemas que podría acarrear la formulación de una teoría evaluativa-normativa del arte como la que él propone. Esta idea dice que la querella que entablan los que juzgan o quieren comprender el arte repercute, a su vez, en la consideración del concepto de arte, confirmando o rechazando con ello el logro de los objetos creados para desafiar la comprensión de nosotros mismos y la determinación de las prácticas humanas en su conjunto. Lo cual afecta, además, a la misma idea de una ontología del arte.

¿Cuál sería entonces la posición de esta disciplina, planteada en términos tan generales, en el acontecer negociador del arte? La ontología del arte quiere ser entendida aquí menos como una teoría que dicta al arte, desde arriba, lo que éste debería ser, que como un elemento reflexivo incrustado en el mismo acontecer, siempre inseguro, del arte. Y, en cuanto elemento, señala Bertram, debe acreditarse siempre en el trato interactivo con configuraciones artísticas. Sin embargo, los escasos análisis de experiencias estéticas ofrecidos podrían despertar algunas dudas acerca de si, finalmente, no nos encontramos ante otra

${ }^{49}$ Rochlitz, Rainer, "Estética y racionalidad. De Adorno a Habermas", traducción de E. Juárez, en Revista Rigel, núm. IV, 2017, p. 86. 
filosofía normativa del arte olvidada del arte, que reduce su variedad a algunas pocas experiencias artísticas, en general, ya ampliamente reconocidas como tales. ¿Acaso esta ausencia no trataría de amortiguar el golpe de lo irreductible?

De todos modos, habría que conceder a Bertram que estamos ante una propuesta que se limita a delinear una orientación teórica para una estética hermenéutica, por cierto, ambiciosa, erudita y muy razonada, y que, por lo tanto, aquellas dudas precipitan lo que esta orientación quisiera contribuir a poner en marcha..$^{50}$ Pero también habría que tomarle la palabra. Pues en la confrontación con las experiencias estéticas, en sus diferentes expresiones, se litiga la posibilidad de combinar la capacidad productiva y la fuerza crítica que pudiese llegar a tener una revitalizada comunión de lo que el paradigma de la autonomía juzgó, con lúcidos argumentos, como incompatible.

\section{Bibliografía}

- Adorno, Theodor W., Ästhetische Theorie, Frankfurt a. M., Suhrkamp, 1973.

- Bertinetto, Alessandro y Bertram, Georg (Eds.), Il bello dell'esperienza. La nuova estetica tedesca, Milano, Christian Marinotti Edizioni, 2016.

- Bertram, Georg W., "El potencial utópico del arte después de Theodor W. Adorno. Una reactualización”, traducido por V. Galfione y E. Juárez, en Galfione, María Verónica y Juárez, Esteban A. (Eds.), Modernidad estética y filosofía del arte. La estética alemana después de Adorno, Tomo I, Córdoba, Ed. 29 de mayo, 2013, pp. 94-101.

- Bertram, Georg W. Kunst als menschliche Praxis. Eine Ästhetik, Suhrkamp, Berlin, 2014 (El arte como praxis bumana. Una estética, traducido por J. F. Zúñiga, Granada, Comares, 2016).

- Bertram, Georg W., Kunst. Eine philosophische Einführung, Stuttgart, Philipp Reclam, 2005.

- Bertram, Georg W., Hermeneutik und Dekonstruktion. Konturen einer Auseinandersetzung der Gegenwartsphilosophie, München, Fink, 2002.

- Bertram, Georg W., Sprachphilosophie zur Einführung, Hamburg, Junius, 2011.

50 Véanse las valiosas discusiones sobre la obra de Bertram reunidas en el dossier, coordinado por José F. Zúñiga, de la revista Estudios Filosóficos, vol. LXVII, núm. 195, 2008. 
- Bertram, Georg W., „Was ist Kunst? Skizze zu einer Ontologie der Kunst“, en Zeitschrift für Ästhetik und Allgemeine Kunstwissenschften, Vol. 62, T. 1, año 2017, pp. 77-94. "“QQué es el arte? Esbozo de una ontología del arte", traducido por M. J. Varela Salinas, en Estudios Filosóficos, Vol. LXVII, 2018, pp. 263-281).

- Bohrer, Karl Heinz, Plötzlichkeit: zum Augenblick des ästhetischen Scheins, Frankfurt a. M., Suhrkamp, 1981.

- Bubner, Rüdiger, „Über einige Bedingungen gegenwärtiger Ästhetik“, en Ästhetische Erfahrung, Frankfurt a. M. Suhrkamp, 1989, pp. 9-51.

- Feige, Daniel, „Zwei Formen des Ästhetischen, zwei Formen des Alltagsbezugs", en Paragrana Vol. 26, nº 2, 2017, pp. 15-25.

- Foucault, Michel, Estética, ética y hermenéutica, traducción de A. Gabilondo Barcelona, Paidós, 1999.

- Gadamer, Hans-Georg, "Estética y hermenéutica”, traducido por J. F. Zúñiga en Daimon. Revista de Filosofía, núm. 12, 1996.

- Gadamer, Hans-Georg, Verdad y método: fundamentos de una bermenéutica filosófica, traducido por A. Agud y R. de Agapito, Salamanca, Sígueme, 1984.

- Gumbrecht, Hans, „Das Nicht-Hermeneutische: Skizze einer Genealogie“ en Hüber, Jörg \& Müller, Alois, Die Wiederkehr des Anderen, Basel, Stroemfeld/Roter Stern, 1996.

- Heidegger, Martin, "El origen de la obra de arte", en Caminos de bosque, traducido por H. Cortés y A. Leyte, Madrid, Alianza, 1998, pp. 11-62.

- Hogh, Philip, „Kraft, Praxis und der blinde Fleck der Geschichte. Zum Geschichtsverständnis in der Gegenwartsästhetik“, en Zeitschrift für kritische Sozialtheorie und Philosophie, Vol. 3, núm. 2, 2016.

- Holznienkemper, Alex, "Kunst als menschliche Praxis. Eine Ästhetik by Georg W. Bertram (review)", en Monatshefte, Vol. 109, núm. 4, 2017.

- Hörisch, Jochen, Die Wut des Verstehens: zur Kritik der Hermeneutik, Frankfurt a. M., Suhrkamp, 1998.

- Jauss, Hans-Robert, „Epilog auf die Forschungsgruppe, ,Poetik und Hermeneutik“", en Graevenitz, Gerhart v. y Marquard, Odo (Eds.), Kontingenz, München, Wilhelm Fink, 1998.

- McDowell, John, Mente y mundo, traducción M. A. Quintana Paz, Salamanca, Ediciones Sígueme, 2003.

- Menke, Christoph, Kraft. Ein Grundbegriff ästhetischer Anthropologie. Mit einem neuen Vorwort, Berlin, Suhrkamp, 2018.

- Menke, Christoph, La fuerza del arte, traducido por N. Bornhauser Neuber, 
Santiago de Chile, Metales Pesados, 2017.

- Menke, Christoph, La soberanía del arte: la experiencia estética según Adorno y Derrida, traducido por R. Sánchez Ortiz de Urbina, Madrid, Visor, 1997.

- Menke, Christoph, "Subjetividad estética. Sobre un concepto fundamental de la estética moderna", en Estética y negatividad, traducción de P. Storandt Diller, Buenos Aires, Fondo de Cultura Económica/Universidad Autónoma Metropolitana, 2011.

- Rebentisch, Juliane, Estética de la instalación, traducido por G. Calderón, Buenos Aires, Caja Negra, 2018.

- Rebentisch, Juliane, „Zur Aktualität ästhetischer Autnomie. Juliene Rebentisch im Gespräch“, en Huber, Tobias y Steinweg, Marcus (Eds.), Inaesthetik. Theses on contemporary art, Berlin/Zurich, Diaphanes, 2008.

- Rochlitz, Rainer, "Estética y racionalidad. De Adorno a Habermas", traducción de E. Juárez, en Revista Rigel, núm. IV, 2017.

- Seel, Martin, „Ästhetik und Hermeneutik. Gegen eine voreilige Verabschiedung", en Die Macht des Erscheinens: Texte zur Ästhetik, Frankfurt a. M., Suhrkamp, 2007.

- Seel, Martin, "Dejarse determinar. Un concepto revisado de autodeterminación", en El balance de la autonomía. Cinco ensayos, traducido por J. Ancona, Barcelona, Anthropos, 2010.

- Seel, Martin, Estética del aparecer, traducido por S. Pereira Restrepo, Buenos Aires, Katz, 2010.

- Sonderegger, Ruth, Für eine Ästhetik des Spiels. Hermeneutik, Dekonstruktion und der Eigensinn der Kunst, Frankfurt a. M., Suhrkamp, 2000.

- Vilar, Gerard, "El concepto de autonomía en la estética alemana reciente", en Estudios Filosóficos, Vol. LVII, 2018.

- Wellmer, Albrecht, Versuch über Musike und Sprache, München, Hanser, 2009.

- Zúñiga, José F. (coord.), Estudios Filosóficos, vol. LXVII, nº 195, 2008.

- Zúñiga, José F., "Hermenéutica, autonomía y valor del arte”, en Rilce, Vol. 35.1, 2019.

Recibido: 09/2019. Aceptado: 11/2019. 